$\underline{\text { Review Article }}$

\title{
MICROSPONGES AS A NEOTERIC CORNUCOPIA FOR DRUG DELIVERY SYSTEMS
}

\author{
SARIPILLI RAJESWARI*, VANAPALLI SWAPNA
}

Department of Pharmaceutical Technology, Maharajah's College of Pharmacy, Phool Baugh, Vizianagaram 535002, Andhra Pradesh, India Email: rajeswarimalli@gmail.com

Received: 16 Feb 2019, Revised and Accepted: 11 Apr 2019

\begin{abstract}
Microsponges (MSPs) are at the forefront of the rapidly developing field of novel drug delivery systems which are gaining popularity due to their use for controlled release and targeted drug delivery. The microsponge delivery system (MDS) is a patented polymeric system consisting of porous microspheres typically 10-25 microns in diameter, loaded with an active agent. They are tiny sponge-like spherical particles that consist of a myriad of interconnecting voids within a non-collapsible structure with a large porous surface through which active ingredient is released in a controlled manner. Microsponge also hold a certification as one of the potential approaches for gastric retention where many oral dosage forms face several physiological restrictions due to non-uniform absorption pattern, inadequate medication release and shorter residence time in the stomach. This type of drug delivery system which is non-irritating, non-allergic, non-toxic, can suspend or entrap a wide variety of substances, and can then be incorporated into a formulated product such as gel, cream, liquid or powder that is why it is called as a "versatile drug delivery system". It overcomes the drawbacks of other formulations such as frequency of dosing, drug reaction, incompatibility with environmental condition. These porous microspheres were exclusively designed for chronotherapeutic topical drug delivery but attempt to utilize them for oral, pulmonary and parenteral drug delivery were also made. The present review elaborates about the multifunctional microsponge technology including its preparation, characterization, evaluation methods along with recent research and future potential.
\end{abstract}

Keywords: Neoteric, Microporous beads, Cornucopia, Solid phase porous microspheres

(C) 2019 The Authors. Published by Innovare Academic Sciences Pvt Ltd. This is an open-access article under the CC BY license (http://creativecommons.org/licenses/by/4.0/) DOI: http://dx.doi.org/10.22159/ijcpr.2019v11i3.34099

\section{INTRODUCTION}

The drug delivery technology landscape has become highly competitive and rapidly evolving. Hence more and more developments in delivery systems are being integrated to optimize the efficacy and cost-effectiveness of the therapy. Drug delivery systems (DDS) that can precisely control the release rates or target drugs to a specific body site have had an enormous impact on the health care system. The challenges faced by drug development industry are first one has sustained release technology for reducing the irritation of a wide range of skin care actives thereby increasing patient compliance and second is enhanced formulation stability ensuring long term product efficacy and extended shelf life.

In the current years, the development of new drugs is not sufficient for the drug treatment, but also requires the development of a suitable drug delivery system at the targeted site. The in vivo fate of the drug is not only determined by the properties of the drug but is also determined by the carrier system which permits a controlled and localized release of the active according to the specific need of the therapy [1]. The biggest challenge up to date is to control the delivery rate of the medicaments by various modern technologies. Carrier technology is the potential solution to these challenges. Microparticles and nanoparticles have been increasingly researched to achieve targeted and sustained release of drugs. These include microspheres, liposomes and nanoparticles etc., which alter the absorption and release characteristics of the drug. Microspheres are unable to control the release rate of the drug from itself. Once the outer wall is ruptured the drug contained within microspheres will be released from it. Liposomes having demerits like lower drug entrapment, difficulty in preparing formulation, limited chemical stability and microbial stability. The microsponge (MSP) based systems can overcome the problems associated with above carrier systems and have been found fuelling the rapid evolution of drug delivery technology.

Microsponge delivery system (MDS), also known as "solid phase porous microsphere" is a patented microparticulate system, comprising of highly cross-linked, polymeric porous microspheres having numerous interconnected voids in the particle, loaded with an active agent within a collapsible structure with a large porous surface. The size of the MSPs ranges from 5-300 $\mu \mathrm{m}$ in diameter and a typical $25 \mu \mathrm{m}$ sphere can have up to 250000 pores and an internal pore structure equivalent to 10 feet in length, providing a total pore volume of about $1 \mathrm{ml} / \mathrm{g}$ for extensive drug retention. The surface can be varied from 20 to $500 \mathrm{~m}^{2} / \mathrm{g}$ and pore volume range from 0.1 to $0.3 \mathrm{~cm}^{3} / \mathrm{g}$. This results in a large reservoir within each MSP which can be loaded with up to its own weight of active agent [2]. MSPs are extremely small, inert, indestructible spheres that do not pass through the skin. Rather, they collect in the tiny nooks and crannies of the skin and slowly release the entrapped drug. The picture of porous MSPs was given in fig. 1 .

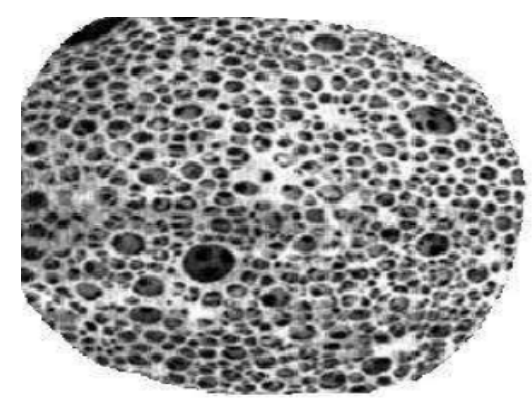

Fig. 1: Porous microsponges [3]

\section{History of microsponges}

The microsponge technology was developed by Won in 1987 and the original patents were assigned to Advanced Polymer Systems, Inc. (Redwood City, California, US). This Company developed a large number of variations of the procedures and those are applied to the cosmetic as well as over-the-counter (OTC) and prescription pharmaceutical products [3]. At the current time, this interesting technology has been licensed to Cardinal Health, Inc., for use in topical products to facilitate the controlled release of active drug into the skin in order to reduce systemic exposure and minimize local cutaneous reactions to active drugs. 
Ideal characteristics of drug candidates suitable for the formulation of microsponge

Actives that can be entrapped into MSPs must meet the following requirements: It should be either fully miscible in the monomer or capable of being made miscible by addition of the small amount of a water immiscible solvent. It should be water immiscible or at most only slightly soluble. It should be inert to monomers. The solubility of actives in the vehicle must be limited to avoid cosmetic problems, not more than 10 to $12 \% \mathrm{w} / \mathrm{w}$ MSPs must be incorporated into the vehicle. Otherwise, the vehicle will deplete the MSPs before the application. The spherical structure of MSPs should not collapse. Polymer design and payload of the MSPs for the active must be optimized for required release rate for a given period. It should be stable in contact with polymerization catalyst and conditions of polymerization $[3,4]$.

\section{Potential features of microsponge drug delivery systems}

MSPs show acceptable stability over a pH ranging from 1 to 11 and at high temperatures (up to $130{ }^{\circ} \mathrm{C}$ ). It Exhibits good compatibility with various vehicles and ingredients [3]. They are characterized by freeflowing properties. These formulations are self-sterilizing as their average pore size is about $0.25 \mu \mathrm{m}$ where the bacteria cannot penetrate the pores [4]. It shows an extended release up to $12 \mathrm{~h}$ [5]. They show high entrapment efficiency up to 50 to $60 \%$ [6]. These formulations can be cost effective even for the cosmetic mass market use where the cost of the materials is important. Improved oil control as it can absorb oil up to 6 times its weight without drying. In contrast to other technologies like microencapsulation and liposome, MDS has a wide range of chemical stability, higher payload and are easy to formulate.

\section{Advantages of microsponge technology}

The advantages of MSP technology were pictorially represented in fig. 2.

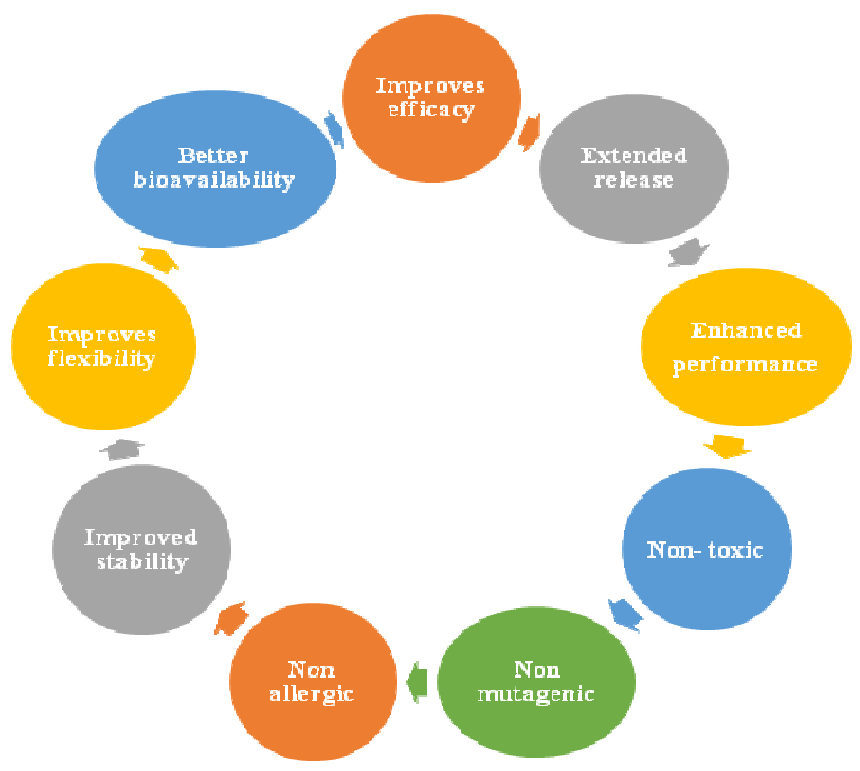

Fig. 2: Advantages of microsponge technology

MSPs have several advantages over other preparations available in the market

\section{Advantages over conventional formulations}

Conventional formulations of topical drugs are intended to work on the outer layers of the skin. Such products release their active ingredients upon application, producing a highly concentrated layer of active ingredient that is rapidly absorbed. When compared to the conventional system, Microsponge systems can prevent excessive accumulation of ingredient within the epidermis and the dermis significantly reducing the irritation of effective drugs without affecting their efficacy $[6,7]$.

\section{Advantages over microencapsulation and liposomes}

Microcapsules cannot usually control the release rate of actives. Once the wall is ruptured, the actives contained within microcapsules will be released. Liposomes suffer from lower payload, difficulty in formulation, limited chemical and microbial stability, whereas microsponge system in contrast to the above system has several advantages like stable over a $\mathrm{pH}$ range of 1-11 and up to temperature of $130{ }^{\circ} \mathrm{C}$, have higher payload up to 50 to $60 \%$, with average pore size of $0.25 \mu \mathrm{m}$ where bacteria cannot penetrate.

\section{Advantages over ointments}

Ointments are often unappealing, greasy and sticky that results in lack of patient compliance. These vehicles require a high concentration of active agents for effective therapy, which results in allergic reactions in significant users. Other drawbacks of topical formulations are uncontrolled evaporation of active ingredient and unpleasant odour.
MSP systems maximize the amount of time that an active ingredient is present either on skin surface or within the epidermis, while minimizing its transdermal penetration into the body.

\section{Limitations}

1. Use of organic solvents as porogen, pose an environmental hazard which may be highly inflammable.

2. In case of the Bottom-Up approach traces of residual monomers have been observed, which may be toxic and hazardous to health.

3. While the limitations seem to be serious, they can be easily overcome by using proper quality control measures coupled with optimization and standardization of procedures e. g., Postmanufacture washing [7].

\section{COMPOSITION}

The MDS contains drug, polymer, vehicle and other additives like plasticizers that help to stabilize the structure. The optimum values of MSPs were given in table 1.

Drugs: Benzoyl peroxide, mupirocin, tretinoin, aceclofenac, ketoprofen, paracetamol, dicyclomine, fluconazole, hydroquinone etc.

Polymers: Ethylcellulose, eudragit, polystyrene, acrylic polymers and PHEMA (Polyhydroxy ethyl methacrylate) etc., as they can form a microsponge "cage".

Vehicles: Dichloromethane, acetone, ethanol etc.

Plasticizers: Triethyl citrate, dibutyl phthalate etc. 
Table 1: Optimum values for microsponge formulation

\begin{tabular}{ll}
\hline Specification & Optimum values \\
\hline Drug: Polymer ratio & $3: 1,4: 1$ and $5: 1$ \\
Amount of drug (g) & 2 \\
PVA (mg) & $30-70$ \\
Inner phase solvent & Ethyl alcohol \\
Amount of inner phase solvent $(\mathrm{ml})$ & $10(\mathrm{ml})$ \\
Amount of water in outer phase $(\mathrm{ml})$ & $200(\mathrm{ml})$ \\
Temperature in inner phase $\left({ }^{\circ} \mathrm{C}\right)$ & 37 \\
Stirrer type & Three blades \\
Stirring rate (rpm) & 500 \\
Stirring time (min) & 60 \\
\hline
\end{tabular}

\section{Preparation of microsponges}

Drug loading in MSPs can take place in two ways, one-step process or by two-step process i.e., Liquid suspension polymerization (Free Radical Suspension Polymerization) and Quasi-emulsion solvent diffusion techniques which are based on physicochemical properties of drug to be loaded. If the drug is typically an inert non-polar material, will create the porous structure which is called asporogen. Porogen drug neither hinders the polymerization nor becomes activated. It is stable to free radicals and can be entrapped with onestep process. Schematic representation of preparation methods of MSPs were shown in fig. 3.

\section{Liquid-liquid suspension polymerization}

Porous microspheres are prepared by this method. In the preparation, the monomers are first dissolved along with active ingredients in a suitable solvent solution and are then dispersed in the aqueous phase, which consists of additives (surfactant, suspending agents, etc.), The polymerization is then initiated by adding catalyst or by increasing temperature or irradiation. The polymerization process leads to the formation of a reservoir type of system, which opens at the surface through pores. In some cases, an inert liquid immiscible with water but completely miscible with monomer is used during the polymerization $[8,9]$ to form the pore network. After the polymerization, the liquid is removed leaving the porous microspheres, i.e. MSPs. Impregnating them within preformed MSPs then incorporates the functional substances. Sometimes solvent may be used for faster and efficient incorporation of the active substances. The MSPs act as atypical carrierfor variety of functional substances, e. g. anti-acne, antiinflammatory, antifungal, rubefacients. When the drug is sensitive to the polymerization conditions, two-step processes isused. The polymerization is performed using substitute Porogen and is replaced by the functional substance under mild experimental conditions. The schematic representation of preparation of porous microspheres by liquid-liquid suspension polymerization $[10,11]$ was shown in fig. 4.

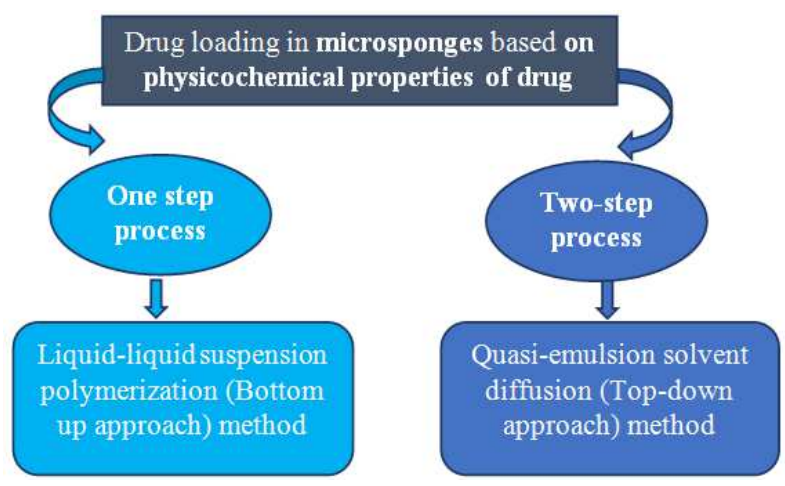

Fig. 3: Schematic representation of preparation methods of microsponges

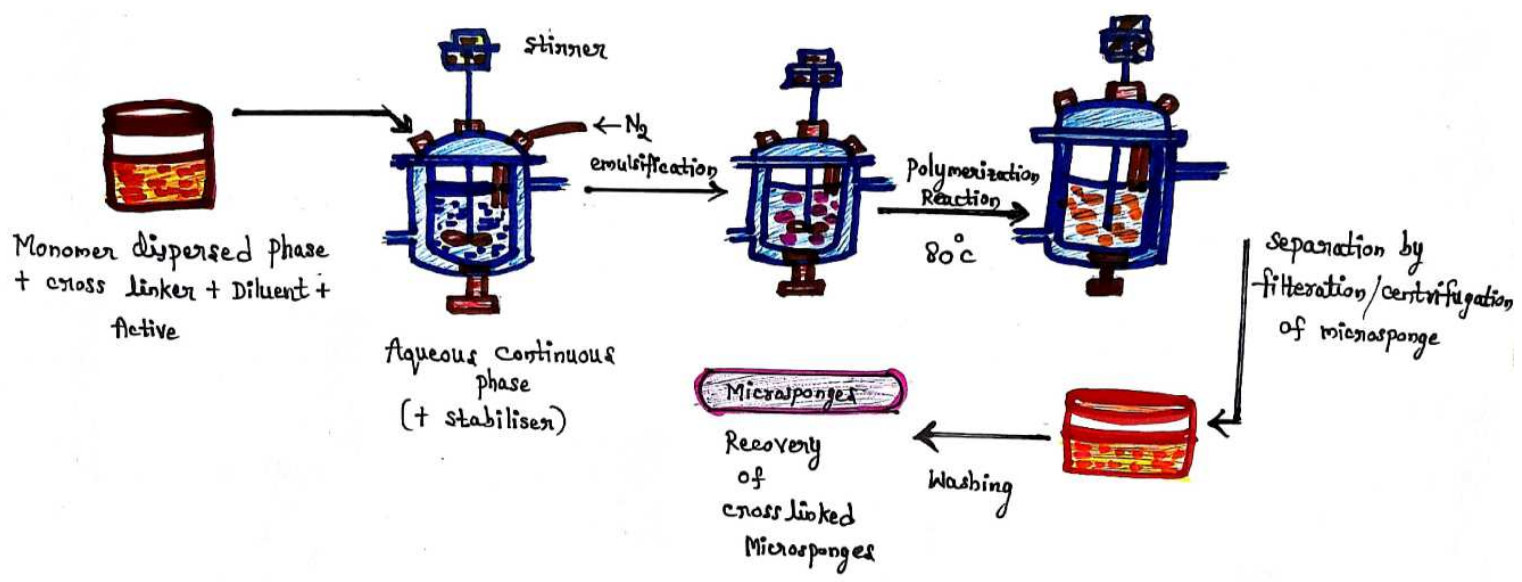

Fig. 4: Schematic representation of preparation of porous microspheres by liquid-liquid suspension polymerization

\section{Quasi-emulsion solvent diffusion}

This method consists of two steps; the internal phase of drugpolymer solution was made in a volatile solvent like ethanol or acetoneor dichloromethane and added to external phase comprising aqueous polyvinyl alcohol (PVA) $[12,13]$ solution with vigorous stirring. Triethyl citrate (TEC) was added at an adequate amount to facilitate plasticity. After emulsification, the mixture was continuously stirred for 2 hto form discrete emulsion globules called quasi-emulsion globules. Then the mixture was filtered to separate the rigid microparticles (MSPs). The product was washed and dried in hot air oven at $40{ }^{\circ} \mathrm{C}$ for $24 \mathrm{~h}[14,15]$. The schematic representation of the preparation of porous microspheres by quasiemulsion solvent diffusion $[16,17]$ was shown in fig. 5 . 


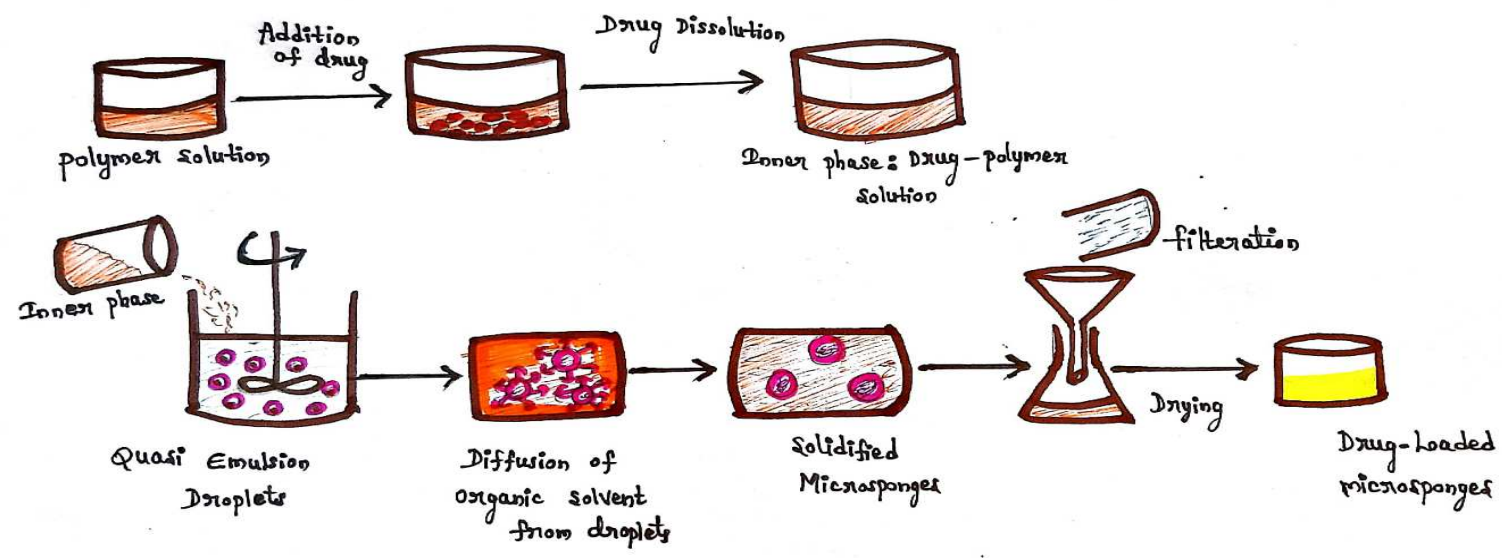

Fig. 5: Schematic representation of preparation of porous microspheres by quasi-emulsion solvent diffusion

In comparison with liquid-liquid suspension polymerization method, this method offers the advantage of less exposure of drug to ambient conditions, low solvent residues in the product because the solvent gets extracted out due to its solubility in aqueous media or due to its volatile nature. Hence, all the MSPs were prepared by a quasiemulsion solvent diffusion method [18-20].

Effect of formulation variables on physical properties of micro sponges (MSP)

\section{Effect of composition of internal and external phases}

It is found that particle size of MSPs were directly proportional to the apparent viscosity of the dispersed phase. Larger the difference between apparent viscosity of dispersed and continuous phase larger the mean particle size of the MSPs. When the dispersed phase with higher viscosity is poured into the continuous phase (external phase), due to the higher viscosity of the internal phase, the globules of the formed emulsion can hardly be divided into smaller particles and bigger droplets are formed resulting in an increase in mean particle size. Good MSPs can be produced only when 3 to $6 \mathrm{ml}$ of internal phase is used [21]. When the amount of dichloromethane is increased from 5 to $15 \mathrm{ml}$ the production yield and drug content of MSPs were found to be decreased which is due to the lower concentration of the drug in the higher volume of internal phase (i.e., dichloromethane). A decrease in volume of external phase (water) results in decrease in production yield, mean particle size and drug content.

\section{Effect of concentration of emulsifier}

When the concentration of emulsifier was decreased the production yield and drug content was increased whereas the mean particle size of MSPs were decreased. An increase in emulsifier concentration can attribute to an increase in apparent viscosity that results in larger emulsion droplets and finally in greater MSPs size.

\section{Effect of drug to polymer ratio}

When the amount of polymer is kept constant but the ratio of drug to polymer is varied the drug loading capacity is not much affected but production yield can be enormously changed from minimum ratio to a maximum one. Another parameter which is affected from drug: polymer ratio change is particle size. It has been observed that when drug amount is increased, the particle size of MSPs is also increased.

Effect of process variableson physical properties of msps [22]

\section{Effect of stirring rate}

Increase in the stirring rate decreases the production yield but the drug content gets increased which indicates that the drug loss is decreased as the stirring rate is increased. This is due to the turbulence created within the external phase due to which polymer gets adhered to the paddle and production yield gets decreased. An increase in stirring rate resulted in a reduction in mean particle size. Any increase in mean particle size at lower stirring rates can be attributed to the increased tendency of globules to coalescence and aggregate. On the other hand, at higher stirring rates a vigorous uniform increased mechanical shear is imposed and this results in a rapid dispersion of the formed droplets which may have less chance of coalescing into bigger droplets which suggests that the size of droplets formed during the encapsulation process may therefore be closely related to the size of the final MSPs produced.

\section{Hypothetical mechanism of action}

\section{In topical formulations [22]}

The active ingredient is added to the vehicle in an entrapped form. As the microsponge particles have an open structure (they do not have a continuous membrane surrounding them), the active is free to move in and out from the particles and into the vehicle until equilibrium is reached. Once the finished product is applied to the skin, the active that is already in the vehicle will be absorbed into the skin, depleting the vehicle, which will become unsaturated, therefore, disturbing the equilibrium. This will start a flow of the active from the MSP particle into the vehicle and from it to the skin, until the vehicle is either dried or absorbed. The MSP particles retained on the surface of the stratum corneum will continue to gradually release the active to the skin, providing prolonged release over time was shown in fig. $\mathbf{6}$. If the active is too soluble in the desired vehicle during compounding of the finished product, it will not provide the desired benefits of gradual release. Instead they will behave as if the active was added to the vehicle in a free form. Therefore, while formulating MSP entrapments, it is important to design a vehicle that has minimal solubilizing power for the actives.

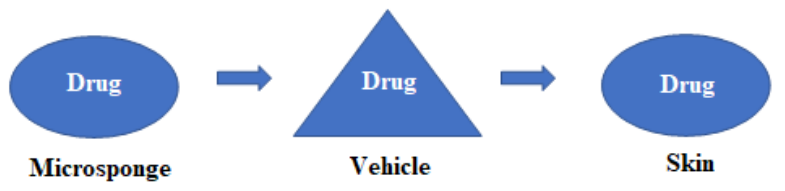

Fig. 6: Schematic representation of the distribution of the loaded material through skin

\section{In oral formulations}

MSPs with $<200 \mu$ m may efficiently be taken up by the macrophages present in the colon, thus exhibiting effective localized drug action at the desired site [21, 22]. They can also increase the lag time for absorption of the drug as these get entrapped on the surface of the colon and thus have the potential for being developed as a colontargeted drug delivery system.

\section{Release mechanism}

The release mechanism of MSPs system is shown in fig. 7 and given as: 


\section{Sustained or timed release}

In the development of a sustained release MSPs, different physical and chemical parameters of the entrapped active substance such as volatility, viscosity, solubility, pore diameter, volume, and resiliency of the polymeric MSPs are evaluated to give necessary sustained release effects.

\section{Release on command}

MSP can be designed to release the given amount of active ingredient over time in response to one or more external triggers.

\section{Pressure release}

MSP system releases fluid or active ingredient when it is pressed or squeezed, thereby replenishing the level of entrapped active ingredient onto the skin. The amount released may also depend upon the release of the sponge and the resiliency of the MSPs [23].

\section{Temperature release}

At room temperature, few entrapped active ingredients can be too viscous to flow suddenly from MSPs onto the skin. With an increase in skin temperature, the flow rate is increased thereby release is also increased.

\section{pH}

It can be achieved by modifying the coating on the MSP [24].

\section{Solubility}

MSPs loaded with water miscible ingredients like antiseptics and antiperspirants will release the ingredient in the presence of water. The release can also be activated by diffusion.

\section{Applications of microsponges}

MDSs are used to enhance the safety and aesthetic quality of topical prescription, over-the-counter and personal care products. It is used mostly for topical and recently for oral administration. Several patents have reported that it can be used as an excipient due to its high loading capacity and sustained release ability. Over-the-counter products that incorporate MSP drug delivery system include numerous moisturizers, specialized rejuvenated products and sunscreens. The list of research works carried out on MSPs with various drugs incorporated into different formulations were given in table 2 .

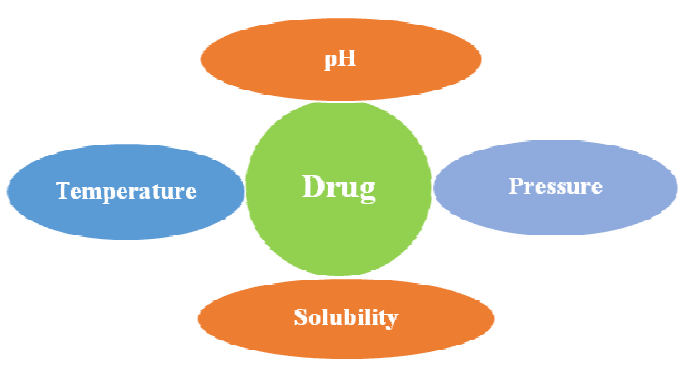

Fig. 7: Mechanism of drug release from MSPs

\section{MSP for topical delivery}

Benzoyl peroxide (BPO) is commonly used in topical formulations for the treatment of acne, with skin irritation as a common side effect. It has been shown that control release of BPO from a delivery system to the skin would reduce the side effect while reducing percutaneous absorption. The entrapped system has released the drug at a slower rate than the system with free BPO.

\section{MSP for oral delivery}

These have been shown to increase the rate of solubilization of poorly water-soluble drugs by entrapping into the MSP systems pores. As these pores are very small, the drug is in effect reduced to microscopic particles resulting in an increase in the surface area that increased the rate of solubilization.

\section{MSP for bone and tissue engineering bone-substitute}

Basic fibroblast growth factor (bFGF) incorporated in a collagen sponge sheet was sustained released in the mouse sub-cutis according to the biodegradation of the sponge matrix and exhibited local angiogenic activity in a dose-dependent manner.

\section{Evaluation tests of microsponges}

\section{Physical characterization of MSPs}

\section{Particle size and size distribution}

Evaluated using either an optical microscope or an electron microscope. This is an extremely crucial step, as the size of the particles greatly affects the texture of the formulation and its stability. Particles larger than $30 \mu \mathrm{m}$ [60-62] can impart gritty feeling and hence particles of sizes between 10 and $25 \mu \mathrm{m}$ are preferred to use in a final topical formulation.

\section{Morphology and surface topography}

For morphology and surface topography [61], various techniques have been used like photon correlation spectroscopy (PCS), Scanning electron microscopy (SEM), transmission electron microscopy (TEM) etc.

\section{Determination of loading efficiency and production yield}

The drug content in the MSPs was determined by high-performance liquid chromatography (HPLC). A sample of drug-containing microsponges $(10 \mathrm{mg})$ was dissolved in $100 \mathrm{ml}$ of methanol. The drug content was calculated from the calibration curve and expressed as loading efficiency. The loading efficiency (\%) of the MSP can be calculated according to Eq. 1.

Loading ef ficiency $=\left[\frac{\text { Actual drug content in MSP }}{\text { Theoretical drug content }}\right] \mathbf{X 1 0 0}$ Eq. 1

Production yield of the microparticles can be determined by accurately calculating the initial weight of the raw materials and the final weight of the MSP obtained by using Eq. 2.

Production yield $=\left[\frac{\text { Production mass }}{\text { Theoretical mass }(\text { polymer }+ \text { drug })}\right] \times 100$ Eq. 2

\section{Determination of true density}

The true density of MSPs can be measured using an ultrapycnometer using helium gas and is calculated from a mean of repeated determinations.

\section{Characterization of pore structure}

Pore volume and diameter are vital in controlling the intensity and duration of the active ingredient. Porosity parameters of MSPs such as intrusion-extrusion isotherms, pore size distribution, total pore surface area, average pore diameters, interstitial void volume, percent porosity filled, shape and morphology of the pores, bulk and apparent density can be determined by using mercury intrusion porosimetry.

\section{Compatibility studies}

The drug-excipients compatibility studies are carried out in order to ensure that there is no inadvertent reaction between the two when formulated into a dosage form. These studies are commonly carried out by recording the differential scanning calorimetry (DSC) of drug and excipients individually and also together and checking for any addition or deletion of any peaks or troughs. Compatibility of drug with reaction adjuncts can also be studied by thin layer chromatography (TLC) and FTIR. Effect of polymerization on the crystallinity of the drug can be studied by powder X-ray diffraction (XRD) and DSC.

\section{Polymer composition}

The polymer composition can affect partition coefficient of the entrapped drug between the vehicle and the MSP system which has a direct influence on the release rate of entrapped drug. It can be studied by plotting cumulative $\%$ drug release against time. 
Table 2: List of research work carried out on microsponges with various drugs incorporated into different formulations [25-62].

\begin{tabular}{|c|c|c|c|c|c|}
\hline $\begin{array}{l}\text { S. } \\
\text { No. }\end{array}$ & Drug & Category & Formulation & Polymers used & Result \\
\hline 1 & Aceclofenac [25] & NSAID & Topical gel & $\begin{array}{l}\text { Eudragit RS 100, } \\
\text { Ethyl cellulose }\end{array}$ & Sustained release up to $8 \mathrm{~h}$ \\
\hline 2 & Acetazolamide [26] & Anti-glaucoma agent & $\begin{array}{l}\text { Topical MSP in-situ } \\
\text { ocular gel }\end{array}$ & $\begin{array}{l}\text { Pluronic F-127, } \\
\text { Ethyl cellulose }\end{array}$ & $\begin{array}{l}\text { Improved therapeutic efficacy } \\
\text { with decreased systemic side } \\
\text { effects }\end{array}$ \\
\hline 3 & Acyclovir [27] & Antiviral agent & Topical gel & $\begin{array}{l}\text { Ethylcellulose, } \\
\text { Carbopol }\end{array}$ & $\begin{array}{l}\text { Sustained release and reduced } \\
\text { side effects }\end{array}$ \\
\hline 4 & Albendazole [28] & Anthelmintic & MSP & Eudragit RS 100 & $\begin{array}{l}\text { Sustained release to treat tissue } \\
\text { parasites }\end{array}$ \\
\hline 5 & Allopurinol [29] & Anti-gout & Floating MSP & $\begin{array}{l}\text { Eudragit EPO, } \\
\text { Ethyl cellulose }\end{array}$ & $\begin{array}{l}\text { Sustained release } \\
\text { Up to } 12 \mathrm{~h}\end{array}$ \\
\hline 6 & Atorvastatin [30] & Antihyperlipidemic & $\begin{array}{l}\text { MSP-based Emulgel for } \\
\text { faster wound healing }\end{array}$ & $\begin{array}{l}\text { Eudragit RS 100, } \\
\text { Carbopol } 934\end{array}$ & $\begin{array}{l}\text { Extended drug release for the } \\
\text { closure of the wound }\end{array}$ \\
\hline 7 & $\begin{array}{l}\text { Benzoyl } \\
\text { Peroxide [31] }\end{array}$ & Skin infections like acne & Topical cream & Ethyl cellulose & $\begin{array}{l}\text { Controlled release with reduced } \\
\text { irritancy }\end{array}$ \\
\hline 8 & Bupropion [32] & CNS stimulant & Floating MSP & Ethyl cellulose & $\begin{array}{l}\text { Controlled release and enhanced } \\
\text { bioavailability }\end{array}$ \\
\hline 9 & $\begin{array}{l}\text { Candesartan cilexetil } \\
{[33]}\end{array}$ & Antihypertensive & MSP & $\begin{array}{l}\text { Eudragit RS 100, } \\
\text { RL 100, S } 100\end{array}$ & $\begin{array}{l}\text { Enhanced solubility and } \\
\text { dissolution rate }\end{array}$ \\
\hline 10 & Celecoxib [34] & NSAID (Arthritis) & Topical MSP gel & $\begin{array}{l}\text { Eudragit RS 100, } \\
\text { Ethyl cellulose }\end{array}$ & Sustained release \\
\hline 11 & Curcumin [35] & Anti-inflammatory & $\begin{array}{l}\text { MSP in oral capsule and } \\
\text { topical drug delivery }\end{array}$ & Ethyl cellulose & $\begin{array}{l}\text { Improved bioavailability and } \\
\text { prolonged drug release, } \\
\text { Enhanced Bioadhesive potential }\end{array}$ \\
\hline 12 & Diclofenac sodium [36] & NSAID & Colon targeted MSP & $\begin{array}{l}\text { Eudragit S 100, L } \\
\text { 100, EPO } 100\end{array}$ & $\begin{array}{l}\text { Enhanced bioavailability, } \\
\text { Site-specific delivery to the colon } \\
\text { with controlled action }\end{array}$ \\
\hline 13 & Domperidone [37] & Antiemetic & MSP loaded capsules & Eudragit RS 100 & $\begin{array}{l}\text { Enhanced bioavailability, } \\
\text { Sustained release }\end{array}$ \\
\hline 14 & Econazole nitrate [38] & Antifungal & Topical MSP Hydrogel & $\begin{array}{l}\text { Eudragit RS } 100, \\
\text { Ethylcellulose, } \\
\text { Carbopol } 934\end{array}$ & Sustained drug release \\
\hline 15 & Erythromycin [39] & Antibiotic to treat acne & MSP gel & Ethyl cellulose & $\begin{array}{l}\text { Extended-release up to } 8 \mathrm{~h} \text { with } \\
\text { reduced side effects }\end{array}$ \\
\hline 16 & Famotidine [40] & Antiulcer & Floating MSP & Eudragit S 100 & Sustained release \\
\hline 17 & 5 -floro uracil [41] & Colo rectal cancer & $\begin{array}{l}\text { Enteric coated HPMC 5- } \\
\text { FU MSP Capsules }\end{array}$ & $\begin{array}{l}\text { HPMC, } \\
\text { Eudragit RS 100, S } \\
\text { 100, L } 100\end{array}$ & $\begin{array}{l}\text { Stimuli }(\mathrm{pH}, \text { microbial }) \\
\text { responsive drug release }\end{array}$ \\
\hline 18 & Hydroxyzine $\mathrm{HCl}$ [42] & $\begin{array}{l}\text { Antihistamine to treat } \\
\text { urticaria and atopic } \\
\text { dermatitis }\end{array}$ & Topical MSP & Eudragit RS 100 & Controlled release \\
\hline 19 & Indomethacin [43] & NSAID & MSP & Eudragit RS 100 & Controlled drug release \\
\hline 20 & Ketoprofen [44] & NSAID (Arthritis) & MSP & Eudragit RS 100 & $\begin{array}{l}\text { Enhanced drug release with } \\
\text { increased bioavailability }\end{array}$ \\
\hline 21 & Lansoprazole [45] & Proton pump inhibitor & $\begin{array}{l}\text { Delayed release } \\
\text { MSP }\end{array}$ & $\begin{array}{l}\text { Eudragit L 100, S } \\
100\end{array}$ & $\begin{array}{l}\text { Avoids degradation in acidic } \\
\text { media }\end{array}$ \\
\hline 22 & Lornoxicam [46-48] & $\begin{array}{l}\text { NSAID (Rheumatoid } \\
\text { arthritis) }\end{array}$ & MSP tablets for colon & Ethyl cellulose & Colon targeting \\
\hline 23 & Mesalamine [49] & $\begin{array}{l}\text { Anti-inflammatory to treat } \\
\text { IBD }\end{array}$ & $\begin{array}{l}\text { Colon-specific MSP } \\
\text { tablet }\end{array}$ & $\begin{array}{l}\text { Eudragit S 100, L } \\
100, \text { RS } 100\end{array}$ & $\begin{array}{l}\text { Enhanced bioavailability of drug } \\
\text { with colon targeting }\end{array}$ \\
\hline 24 & $\begin{array}{l}\text { Metoprolol succinate } \\
{[50]}\end{array}$ & Antihypertensive & Colon specific MSPtablet & Ethyl cellulose & $\begin{array}{l}\text { Microflora activated sustained } \\
\text { release colonic system }\end{array}$ \\
\hline 25 & $\begin{array}{l}\text { Mitiglinide calcium } \\
\text { [51] }\end{array}$ & $\begin{array}{l}\text { Antidiabetic } \\
\text { (type-II diabetes) }\end{array}$ & $\begin{array}{l}\text { Gastroretentive } \\
\text { MSP }\end{array}$ & $\begin{array}{l}\text { Eudragit RS } 100, \\
\text { Ethyl cellulose }\end{array}$ & $\begin{array}{l}\text { Prolonged drug release with } \\
\text { reduced dosing frequency }\end{array}$ \\
\hline 26 & $\begin{array}{l}\text { Mometasone furoate } \\
\text { [52] }\end{array}$ & $\begin{array}{l}\text { Corticosteroid to treat } \\
\text { psoriasis }\end{array}$ & Topical MSP & Eudragit RS 100 & $\begin{array}{l}\text { Controlled release with reduced } \\
\text { side effects }\end{array}$ \\
\hline 27 & Mupirocin $[53,54]$ & $\begin{array}{l}\text { Topical antibiotic for skin } \\
\text { infections }\end{array}$ & MSP loaded emulgel & $\begin{array}{l}\text { Ethylcellulose, } \\
\text { Tween } 20 \text {, } \\
\text { Span } 20\end{array}$ & $\begin{array}{l}\text { Therapeutic drug deposition up } \\
\text { to } 24 \mathrm{~h}\end{array}$ \\
\hline 28 & Nicorandil [55] & Potassium channel opener & $\begin{array}{l}\text { MSP sustained release } \\
\text { tablet }\end{array}$ & $\begin{array}{l}\text { HPMC K15M, } \\
\text { K100M, } \\
\text { EudragitS100, } \\
\text { RSP0, RLPO }\end{array}$ & Controlled release up to $24 \mathrm{~h}$ \\
\hline 29 & Oxybenzone [56] & $\begin{array}{l}\text { Broadspectrum sunscreen } \\
\text { agent }\end{array}$ & MSP topical gel & Ethyl cellulose & $\begin{array}{l}\text { Enhanced topical retention for } \\
\text { prolonged period with reduced } \\
\text { toxicity and irritation }\end{array}$ \\
\hline 30 & Piroxicam [57] & $\begin{array}{l}\text { NSAID } \\
\text { (Arthritis) }\end{array}$ & $\begin{array}{l}\text { MSP Topical gel for } \\
\text { transdermal delivery }\end{array}$ & $\begin{array}{l}\text { Eudragit RS } 100, \mathrm{~S} \\
\text { 100, RL 100, } \\
\text { Carbopol } 934\end{array}$ & $\begin{array}{l}\text { Enhanced dissolution and drug } \\
\text { release with reduced side effects }\end{array}$ \\
\hline 31 & Prednisolone [58] & Corticosteroid & Colon targeted & Eudragit S 100, & Controlled release with \\
\hline
\end{tabular}




\begin{tabular}{|c|c|c|c|c|c|}
\hline & & & $\begin{array}{l}\text { MSPtablets to treat } \\
\text { ulcerative colitis }\end{array}$ & Ethyl cellulose & enhanced mucoadhesion \\
\hline 32 & Ritonavir [59] & Antiviral agent & Topical MSP gel & $\begin{array}{l}\text { Ethyl cellulose, } \\
\text { Carbopol } 940\end{array}$ & Improved oral bioavailability \\
\hline 33 & $\begin{array}{l}\text { Serataconazole nitrate } \\
{[60]}\end{array}$ & Antifungal & Topical MSP & $\begin{array}{l}\text { Eudragit RS 100, } \\
\text { Carbopol } 934\end{array}$ & $\begin{array}{l}\text { Improved product efficacy with } \\
\text { controlled drug release }\end{array}$ \\
\hline 34 & Tolnaftate $[61,62]$ & Antifungal & Topical MSP gel & $\begin{array}{l}\text { Eudragit RL 100, } \\
\text { RS } 100\end{array}$ & Better drug release \\
\hline
\end{tabular}

All these formulations were prepared by using Quasi-emulsion solvent diffusion method, MSP-Microsponges.

\section{Resiliency (viscoelastic properties)}

It is used to define the firmness of the final formulation. This influences the collapsible characteristic as well as drug release of the MSPs.

\section{Dissolution studies}

Dissolution profile of MSPs can be studied by the use of dissolution apparatus USP XXIII with a modified basket consisting of $5 \mu \mathrm{m}$ stainless steel mesh. The speed of the rotation is $150 \mathrm{rpm}$. The dissolution medium is selected while considering the solubility of actives to ensure sink conditions. Samples from the dissolution medium can be analysed by a suitable analytical method at various intervals.

\section{Kinetics of release}

The drug release mechanism and the release profile differences among MSP can be determined by the drug released amount versus time. The release data can be analysed with the following mathematical models given in Eq. 3 .

$$
Q=k_{1} t^{n} \operatorname{or} \log Q=\log k_{1}+n \log t
$$

Where $\mathrm{Q}$ is the amount of the drug released at the time (h), $\mathrm{n}$ is a diffusion exponent which indicates the release mechanism, and $\mathrm{k}_{1}$ is a constant characteristic of the drug-polymer interaction. From the slope and intercept of the plot of $\log Q$ versus $\log t$, kinetic parameters $n$ and $k_{1}$ were calculated. For comparison purposes, the data was also subjected to Eq. 4, which may be considered as a simple Higuchi type equation.

Eq. 5 representing release data dependent on the square root of time, would give a straight-line release profile, with $\mathrm{k}_{2}$ presented as a root time dissolution rate constant and $\mathrm{C}$ as a constant.

$$
Q=k_{2} t^{0.5}+C
$$

\section{Physicochemical characterization of MSPs}

\section{Scanning electron microscopy}

For morphology and surface topography, prepared MSPs can be coated with gold-palladium under an argon atmosphere at room temperature.

\section{Fourier transform infrared spectroscopy}

FTIR [56-61] spectroscopy is carried out for the pure drug, polymer and the drug-polymer physical mixture and microsponge formulations. The samples are incorporated in potassium bromide discs and evaluated. The peaks corresponding to the characteristics bands of the drug should be preserved in the spectra of the MSPs to indicate that no chemical interaction or changes took place during the preparation of the formulation.

\section{Powder X-ray diffraction}

XRD can be performed for both pure drug, polymer and MSP formulation to investigate the effect of polymerization on the crystallinity of the drug. The disappearance of the characteristic peaks of the drug in the formulation would indicate that the drug is disappeared at a molecular level in the polymer matrix.

III. Safety considerations: Safety studies of MSPs can be confirmed by:

$>$ Allergenicity in guinea pigs

$>$ Eye irritation studies in rabbits

$>$ Mutagenicity in bacteria

$>$ Oral toxicity studies in rats

$>$ Skin irritation studies in rabbits

Some of the patents filed on MSPs were given in table 3.

\begin{tabular}{|c|c|c|c|}
\hline S. No. & Inventors & Publication date & Patent number \\
\hline 1 & Won & 1987 & US4690825 \\
\hline 2 & Dean et al. & 1989 & US4863856 \\
\hline 3 & Katz et al. & 1992 & US5135740 \\
\hline 4 & Chantal et al. & 1994 & US5679374 \\
\hline 5 & Ray & 1996 & US5725869 \\
\hline 6 & Straub et al. & 1999 & US6395300 \\
\hline 7 & Tomlinson et al. & 2001 & US6211250 \\
\hline 8 & Shefer et al. & 2002 & US20030232091 \\
\hline 9 & Singh & 2003 & US20030008851 \\
\hline 10 & Maurizio & 2004 & US20040247632 \\
\hline 11 & Steven et al. & 2005 & US20050271702 \\
\hline 12 & Malek & 2007 & US20070141004 \\
\hline 13 & Halliday & 2008 & US20080160065 \\
\hline 14 & Karyion Inc & 2009 & US7604814 \\
\hline 15 & Sara Vargas & 2010 & US7740886 \\
\hline 16 & Celmatrix Corporation & 2011 & US7749489 \\
\hline 17 & Karykion Corporation & 2012 & US8323672 \\
\hline 18 & Ferring B. V & 2013 & US8361273 \\
\hline 19 & Stiefel Research Australia Pvt Ltd & 2014 & US8758728 \\
\hline 20 & Galderma Research and Development & 2015 & US8936800 \\
\hline
\end{tabular}

Table 3: Patents filed related to microsponges

The list of marketed formulations of MSPs with brand name and manufacturers were given in table 4 . 
Table 4: Marketed formulations of MSPs

\begin{tabular}{|c|c|c|}
\hline Brand name & Drug & Manufacturer \\
\hline $\operatorname{Carac}^{\mathrm{TM}}$ & 5-Fluorouracil & Dermic Labs, Inc, US \\
\hline Retin-A Micro ${ }^{\circledR}$ & Tretinoin & A. P. Pharma, Inc, US \\
\hline Melanin Microsponge ${ }^{\circledR}$ & Melanin & Advanced Polymer System Inc, US \\
\hline NeoBenz ${ }^{\circledR}$ & Benzoyl peroxide & Skin media, Inc, US \\
\hline Line Eliminator Dual Retinol Facial Treatment & Retinol & Avon, New York, US \\
\hline Retinol cream & Retinol & Biomedic \\
\hline Ultra Guard & Dimethicone & Scott Paper Co., Pennsylvania, US \\
\hline Lactrex $^{\mathrm{TM}} 12 \%$ Moisturizing Cream & Ammonium lactate & SDR Pharmaceuticals, Inc, Andover, NJ, US \\
\hline
\end{tabular}

\section{Future prospects}

The real challenge in the future is the development of the delivery system for the oral peptide delivery. The use of bioerodible and biodegradable polymers for the drug delivery enables it for the safe delivery of the active material. As these porous systems have also been studied for the drug delivery through the pulmonary route which shows that these systems can show effective drug release even in the scarce of the dissolution fluid, thus colon is an effective site for the targeting of drug release. These carriers are also required to be developed for alternative drug administration routes like parenteral and pulmonary. These particles can also be used as the cell culture media and thus can also be employed for stem cell culture and cellular regeneration in the body. Due to their elegance, these carrier systems have also found their application in cosmetics. These developments enabled researchers to utilize them variably. An interesting application of the MSP technology could be in oral cosmetics, such as to sustain the release of volatile ingredients, thus increasing the duration of the 'fresh feel'. MSPs of such volatile ingredients may be easily incorporated in toothpastes or mouth washes. In long lasting coloured cosmetics such as rouge or lipsticks where MSPs help in uniform spreading and improving covering power. Due to their versatile nature and multifunctional uses, it holds a breaking new ground opportunity for pharmaceutical and cosmetic technology which can be a winning strategy for the coming future.

\section{CONCLUSION}

In order to overcome the drawbacks of the conventional dosage form and to improve the safety and efficacy of drugs, MSPs were introduced. It is a unique technology for the controlled release of topical agents and consists of microporous beads loaded with a wide range of actives which release them in a controlled manner in response to trigger. It has a distinct advantage over the existing conventional topical dosage forms for the treatment of tropical diseases. The potential of MSPs for targeting the drug molecule to the various parts of GIT including ascending colon and stomach were already explained by various researchers. It enhances compressibility and produces mechanically strong tablet owing to the plastic deformation of the sponge-like structure. It has been successfully studied for colon targeting and their compressed tablets can be used for chronic purposes. It holds a promising future in various pharmaceutical applications in the coming years as they have unique properties like an extended release, reduced irritancy, small size, selfsterilize and compatible with most of the vehicles and ingredients, which makes them flexible to develop novel formulations. It is a highly competitive technology and more research is being carried out to optimize cost as well as the efficacy of therapy. Thus, it is a very emerging field which is needed to be explored.

\section{AUTHORS CONTRIBUTIONS}

All the author have contributed equally

\section{CONFLICT OF INTERESTS}

Declare none

\section{REFERENCES}

1. Mohite P, Khanage S. Recent advances in microsponges drug delivery system. J Crit Rev 2016;3:9-16.

2. Jadhav N, Patel V. Microsponge delivery system: an updated review, current status and future prospects. J Sci Innovative Res 2013;2:1097-110.
3. Mandava S, Thavva V. Novel approach: microsponge drug delivery system. Int J Pharm Sci Res 2012;3:967-80.

4. Jagtap S, Karale A. Microsponge: a novel topical drug delivery system. J Drug Delivery Res 2014;3:1-9.

5. Kumari P, Mishra S. A comprehensive review on novel microsponges drug delivery approach. Asian J Pharm Clin Res 2016;9:25-30.

6. Charde M, Ghanawat P. Microsponge a novel new drug delivery system: a review. Int J Adv Pharm 2013;2:63-70.

7. Patel U. A review-recent research on microsponge a novel new drug delivery system. Int J Adv Pharm 2018;7:10-6.

8. Aloorkar NH, Ingale DJ. Microsponges as innovative drug delivery systems. Int J Pharm Sci Nanotechnol 2012;5:1597-606.

9. Deshwal S, Saxena A. Microsponge delivery system: an overview. Int J Biopharma 2014;5:39-46.

10. Jyoti J, Kumar S. Innovative and novel strategy: microsponges for topical drug delivery. J Drug Delivery Ther 2018;8:28-34.

11. Ayan Kumar K, Banhishikha K. A novel approach on microsponge: multifunctional modern dosage form. Int J Pharm Sci Rev Res 2018;51:64-72.

12. Junqueira $M$, Bruschi $M$. A review about the drug delivery from microsponges. AAPS PharmSciTech 2018;19:1501-11.

13. Patil S, Behera A. Spherical crystallization in solubility enhancement. Adv Drug Delivery 2018;4:1-41.

14. Pawan S, Prashant B. A new era in topical formulationsmicrosponge drug delivery system. Int J Pharm Sci Res 2016;7:2756-61.

15. Osmani R, Aloorkar N. Microsponge based drug delivery system for augmented gastroparesis therapy: formulation development and evaluation. Asian J Pharm Sci 2015;10:442-51.

16. Kapoor D, Patel M, Vyas R. A review on microsponge drug delivery system. J Drug Delivery Ther 2014;4:29-35.

17. Arijit G, Sougata J. Tailoring effect of microsponge for targeted drug delivery. J Sci Innovative Res 2013;2:1073-82.

18. Srivastava R, Pathak K. Microsponges: a futuristic approach for oral drug delivery. Expert Opin Drug Delivery 2012;9:863-78.

19. Kumar S, Tyagi L. Microsponge delivery system: a unique technology for delivery of active ingredients. Int J Pharm Sci Res 2011;2:3069-80.

20. Sarat Chandra Prasad, Ajay M. Microsponge drug delivery system: a review. J Pharm Res 2011;4:1381-4.

21. Kaity S, Maiti S. Microsponges: a novel strategy for drug delivery system. J Adv Pharm Technol Res 2010;1:283-90.

22. Çomoglu T, Gönül N. The effects of pressure and direct compression on tableting of microsponges. Int J Pharm 2002;242:191-5.

23. Vyas SP, Khar RK. Targeted and controlled drug delivery-novel carrier system. CBS Publication, New Delhi, Edition 1; 2002. p. 453.

24. Won R. Method for delivering an active ingredient by controlled time release utilizing a novel delivery vehicle which can be prepared by a process utilizing the active ingredients as a porogen, US, Patent No. 4690825; 1987.

25. Patel U. Formulation and development of Aceclofenac loaded microsponges for topical delivery using quality by design approach. Int J Adv Pharm 2018;7:17-32.

26. Obiedallah M, Abdel Mageed A, Elfaham T. Ocular administration of acetazolamide microsponges in situ gel formulations. Saudi Pharma J 2018;26:909-20.

27. Development and evaluation of some microsponge loaded medicated topical formulations of acyclovir. Int J Pharm Sci Res 2014;5:1395-410. 
28. Abdellatif A, Zayed G, Kamel H, Mohamed A, Arafa W, Khatib A. A novel controlled release microsponges containing albendazole against haemonchus contortus in experimentally infected goats. J Drug Delivery Sci Technol 2018;43:469-76.

29. Patel D. Formulation and evaluation of floating microsponges of allopurinol. pharma science monitor. Int J Pharm Sci 2016; 7:135-54.

30. Rajput K, Tankar A, Tekade A. Atorvastatin loaded microsponges based emu oil emulgel for faster wound healing. Anna Pharmacol Pharma 2018;3:1-10.

31. Jelvehgari M, Siahi Shadbad M, Azarmi S, Martin G, Nokhodchi A. The microsponge delivery system of benzoyl peroxide: preparation, characterization and release studies. Int J Pharm 2006;308:124-32.

32. Muralidhar P. Formulation and optimization of bupropion $\mathrm{HCl}$ microsponges by $2^{3}$ factorial design. Int J Pharm Sci Res 2017;8:1134-44.

33. Abd Alhammid S. Enhancement of the solubility and the dissolution rate of candesartan cilexetil using microsponge technology. Asian J Pharm Clin Res 2018;11:385.

34. Kadam V, Patel V, Karpe M, Kadam V. Design, development and evaluation of celecoxib-loaded microsponge-based topical gel formulation. Appl Clin Res Clin Trials Regulatory Affairs 2016;3:44-55.

35. Bhatia M, Saini M. Formulation and evaluation of Curcumin microsponges for oral and topical drug delivery. Prog Biomater 2018;7:239-48.

36. Janaki Devi S, Ramanamurthy K. Design of a novel colon targeted microsponges loaded with diclofenac sodium using three different polymers. Int Res J Pharm 2018;9:10-9.

37. Osmani R, Aloorkar N, Thaware B, Kulkarni P, Moin A, Hani U. Microsponge based drug delivery system for augmented gastroparesis therapy: formulation development and evaluation. Asian J Pharm Sci 2015;10:442-51.

38. Resmi DS. Formulation and evaluation of topical econazole nitrate microsponge loaded hydrogel. Int J Pharm Pharm Res 2018;12:27-64.

39. Ravi R. Standardization of process parameters involved erythromycin microsponges by quasi-emulsion solvent diffusion method. Int J Pharm Dev Technol 2013;3:28-34.

40. Charagonda S, Puligilla R, Ananthula M, Bakshi V. Formulation and evaluation of famotidine floating microsponges. Int Res J Pharm 2016;7:62-7.

41. Gupta A, Tiwari G, Srivastava R. Enteric coated HPMC capsules plugged with 5-FU loaded microsponges: a potential approach for treatment of colon cancer. Brazilian J Pharm Sci 2015;51:591-605.

42. Zaki C, Latif R, Soliman I. In vitro and in vivo evaluation of hydroxyzine hydrochloride microsponges for topical delivery. AAPS PharmSciTech 2011;12:989-1001.

43. Rajitha I. Development and evaluation of a microsponge drug delivery system of indomethacin. Int J Pharm 2017;7:125-31.

44. Comoglu T, Gonul N, Baykara T. Preparation and in vitro evaluation of modified release ketoprofen microsponges. Il Farmaco 2003;58:101-6.

45. Imran Tadwee, Sadhana S. Formulation and development of microsponge based delayed release dosage form of lansoprazole. Int J Pharm Sci Res 2018;9:824-31.
46. Vivekanand K. Fabrication and characterization of lornoxicam loaded microsponge tablets for colon delivery. Acta Sci Pharm Sci 2018;2:3-11.

47. Panday P, Shukla N, Sisodiya D, Jain V, Mahajan S. Design and characterization of microsponge loaded controlled release epicutaneous gel of lornoxicam. Appl Med Res 2015;1:16.

48. Karthika R, Elango. Formulation and evaluation of lornoxicam microsponge tablets for the treatment of arthritis. Int J Pharm Innovations 2012;3:29-40.

49. Janaki Devi S, Ramanamurthy K. Development of colontargeted microsponges for the treatment of inflammatory bowel disease. Indian J Pharm Sci 2018;80:604-9.

50. Jain P. Formulation and evaluation of colon specific tablet containing microsponges of metoprolol succinate. Int J Pharm Life Sci 2015;6:4851-6.

51. Mahmoud D, Shukr M. Gastroretentive microsponge as a promising tool for prolonging the release of mitiglinide calcium in type-2 diabetes mellitus: optimization and pharmacokinetics study. AAPS PharmSciTech 2018;19:2519-32.

52. Rekha, Manjula B. Formulation and evaluation of microsponges for topical drug delivery of mometasone furoate. Int J Pharm Pharm Sci 2011;3:133-7.

53. Mohan Kumar V. Formulation and evaluation of microsponges for topical drug delivery of mupirocin. Int J PharmTech Res 2013;5:1434-40.

54. Amrutiya N, Bajaj A, Madan M. Development of microsponges for topical delivery of mupirocin. AAPS PharmSciTech 2009;10:402-9.

55. Patel S, Patel M. Formulation and evaluation of microsponge based nicorandil sustained released tablet. J Sci Res 2017;9:285

56. Pawar A, Gholap A, Kuchekar A, Bothiraja C, Mali A. Formulation and evaluation of optimized oxybenzone microsponge gel for topical delivery. J Drug Delivery 2015;2015:1-9.

57. Rajab N, Jawad M. Formulation and in vitro evaluation of piroxicam microsponge as a tablet. Int J Pharm Pharm Sci 2015;8:104-14.

58. Kumari A, Jain A, Hurkat P, Tiwari A, Jain S. Eudragit S100 coated microsponges for colon targeting of prednisolone. Drug Dev Ind Pharm 2017;44:902-13.

59. Patil N. A research on formulation and evaluation of microsponge loaded in topical gel of ritonavir. World J Pharm Pharm Sci 2018;7:855-96.

60. Kadnor N, Pande V, Kadam R, Upadhye S. Fabrication and characterization of sertaconazole nitrate microsponge as a topical drug delivery system. Indian J Pharm Sci 2015;77:675.

61. Yadav V, Jadhav P, Dombe S, Bodhe A, Salunkhe P. Formulation and evaluation of microsponge gel for topical delivery of an antifungal drug. Int J Appl Pharm 2017;9:30.

62. Kumari P, Misra S. Formulation and evaluation of tolnaftate microsponges loaded gels for treatment of dermatophytosis. Eur J Pharm Med Res 2017;4:326-35.

63. Desavath M. Design, development and characterization of valsartan microsponges by quasi emulsion technique and the impact of stirring rate on microsponge formation. J Appl Pharm Sci 2017;7:193-8. 